\title{
TENSÃo DE ÁGUA NO SOLO PARA O REINÍCIO DA IRRIGAÇÃo DE MILHO VERDE NO SEMIÁRIDO
}

\author{
FERNANDO GOMES DA SILVA ${ }^{1}$, IGNACIO ASPIAZÚ ${ }^{2}$, RENATO MENDES DE OLIVEIRA ${ }^{3}$, \\ KAREN MARCELLE DE JESUS SILVA ${ }^{4}$, SILVÂNIO RODRIGUES DOS SANTOS ${ }^{5}$, \\ ARLEY FIGUEIREDO PORTUGAL ${ }^{6}$, JOSÉ ALOÍSIO ALVES MOREIRA7 ${ }^{7}$, \\ ORLANDO GONÇALVES BRITO ${ }^{8}$ e NATANAEL PEREIRA DA SILVA ${ }^{9}$
}

\author{
1,2,3,5,9 Universidade Estadual de Montes Claros - UNIMONTES. Av. Reinaldo Viana, 2630, Janaúba - MG, CEP.: 39440-000. \\ fernandogomesagronomo@gmail.com,aspiazu@gmail.com,renatoagronomo@hotmail.com, \\ silvaniors@yahoo.com.br,nathannaelpds@hotmail.com. \\ ${ }^{4}$ Universidade Federal de Lavras - UFLA. Av. Doutor Sylvio Menicucci, 1001 - Kennedy, Lavras - MG, CEP.: $37200-000$. \\ karen_marcelle@hotmail.com. \\ ${ }^{6,7}$ Embrapa Milho e Sorgo. Rod MG 424 Km 45, Zona Rural, Sete Lagoas - MG, CEP.: 35701-970. \\ arley.portugal@embrapa.br,jose.aloisio@embrapa.br \\ ${ }^{8}$ Universidade Federal dos Vales do Jequitinhonha e Mucuri-UFVJM. \\ Rodovia MGT 367 - Km 583, 5000 - Alto da Jacuba, Diamantina - MG, CEP.: 39100-000. orlandocefet@yahoo.com.br.
}

Revista Brasileira de Milho e Sorgo, v.17, n.2, p. 190-200, 2018

\begin{abstract}
RESUMO_O objetivo deste trabalho foi determinar em campo a tensão de água do solo adequada para o reinício da irrigação do milho verde no semiárido. $\mathrm{O}$ experimento constou de seis valores de tensão matricial da água do solo (20 kPa, $40 \mathrm{kPa}, 60 \mathrm{kPa}, 80 \mathrm{kPa}, 100 \mathrm{kPa}$ e $120 \mathrm{kPa}$ ) testadas em uma cultivar de milho, o hibrido duplo AG 1051. O experimento foi instalado no período de inverno de 2013, nos meses de agosto a novembro, num delineamento experimental de blocos casualizados (DBC), com quatro repetições, conduzidos na fazenda experimental da Embrapa Milho e Sorgo em Nova Porteirinha, MG. Foram avaliadas as variáveis: produtividade de espigas sem palha $\left(\mathrm{t}\right.$ ha $\left.{ }^{-1}\right)$, número de espigas totais e comerciais por hectare, comprimento de espigas com palha e sem palha e diâmetro de espigas comerciais. Dentre os resultados pode-se constatar que os maiores valores para as variáveis de morfologia e de produtividade foram obtidos quando a irrigação foi efetuada com tensão próxima de $50 \mathrm{kPa}$, tornando-a a tensão mais adequada para o uso racional da água no manejo da irrigação do milho verde.
\end{abstract}

Palavras-chave: Zea mays L., déficit hídrico, manejo da irrigação, resistência elétrica.

\section{SOIL WATER TENSION FOR REWATERING GREEN CORN IN THE SEMIARID}

\begin{abstract}
The objective of this work was to determine the adequate water tension for rewatering green corn at field conditions in the semiarid. The experiment consisted of six values of matric soil water tension $(20 \mathrm{kPa}, 40$ $\mathrm{kPa}, 60 \mathrm{kPa}, 80 \mathrm{kPa}, 100 \mathrm{kPa}$ and $120 \mathrm{kPa}$ ) and one maize cultivar, the double hybrid AG1051. The experiment was installed in the 2013 winter season, from August to November, in a randomized blocks design (DBC), with four replicates, and conducted at the experimental farm belonging to Embrapa Maize and Sorghum in Nova Porteirinha, MG. Morphological parameters were evaluated such as plant height, leaf area index and dry mass, and also the yield parameters such as weight of spikes with straw and without straw $\left(\mathrm{t} \mathrm{ha} \mathrm{a}^{-1}\right)$, number of total and commercial spikes per hectare, diameter of commercial spikes and length of commercial spikes with and without straw. The highest values for the morphology and productivity variables were obtained when irrigation was carried out with a tension close to $50 \mathrm{kPa}$, which proved to be the most suitable tension for the rational use of water in the irrigation management of green corn. Keywords: Zea mays L., water deficit, irrigation management, electrical resistance.
\end{abstract}


O milho (Zea mays L.) é uma das plantas cultivadas que apresenta maior eficiência comercial. Originado das Américas, mais especificamente do México, é utilizado na alimentação humana em diversas formas de grãos secos e verdes ou na fabricação de rações. $\mathrm{O}$ cultivo de milho destinado à produção de milho verde vem aumentando de forma significativa em função de sua lucratividade, pois na forma de grãos verdes o valor de comercialização é maior quando comparado com o milho na forma de grãos secos.

O cultivo do milho verde se realiza durante todo o ano, com a finalidade de atender ao mercado consumidor. No entanto, na época da seca, necessita ser irrigado. $\mathrm{O}$ incentivo dado à agricultura irrigada ampliou o interesse do agricultor pelo cultivo de mi1ho. Esse apoio fez com que o milho fosse cultivado na entressafra e, consequentemente, se tornasse atividade de grande importância nos estados nordestinos e do Sudeste.

Nos dias atuais, a adoção de técnicas de manejo que aumentem o potencial da produção agrícola, como a avaliação da viabilidade da irrigação, assume grande importância devido à escassez de recursos hídricos e pelo fato da agricultura irrigada ser um setor que demanda muita água. Conhecer as necessidades hídricas das culturas garante aumento da produção e proporciona menores impactos ambientais sobre este recurso natural.

Existem diferentes métodos para se controlar a irrigação, no que se refere ao momento de se irrigar e quanto à quantidade a ser fornecida à cultura. Um desses métodos é o de medida de tensão de água no solo por meio da resistência à passagem de corrente elétrica com uso de blocos de resistência.

Blocos de resistência são equipamentos que medem a tensão com que a água é retida pelo solo, a qual afeta diretamente a absorção de água pelas plan- tas. Tais medidas podem ser utilizadas para avaliar indiretamente a deficiência hídrica de uma cultura. Em geral, para a maioria das culturas, bons rendimentos têm sido obtidos quando são mantidas baixas tensões de água no solo. Para tanto, são necessárias irrigações frequentes, as quais não são recomendadas porque aumentam os custos de produção e as perdas de água por evaporação. Assim, deve-se adequar o manejo de irrigação à produção do milho verde, com ênfase na diminuição da quantidade de água disponibilizada à cultura durante o ciclo de irrigação.

Esta pesquisa buscou definir a tensão de água do solo que propicia reduzir gastos e otimizar a produtividade do milho verde no semiárido do norte mineiro.

\section{Material e Métodos}

O experimento foi conduzido na fazenda experimental da Embrapa Milho e Sorgo, situada no município de Nova Porteirinha, Minas Gerais. Região localizada no semiárido brasileiro, com coordenadas longitude $43^{\circ} 16^{\prime} 18,2^{\prime}$ ' W e latitude $15^{\circ} 49^{\prime} 51^{\prime \prime} \mathrm{S}$, a $540 \mathrm{~m}$ de altitude e clima Aw segundo a classificação de Köppen (Ometto, 1981), isto é, tropical com inverno seco e temperatura média do ar do mês mais frio superior a $18^{\circ} \mathrm{C}$.

Os solos do local são classificados como Latossolos Vermelho-Amarelos, com textura média, profundos ou muito profundos, normalmente muito porosos, mesmo aqueles com elevados teores de argila. Com base na análise granulométrica realizada, na camada de 0-20 cm constataram-se teores médios de $120 \mathrm{~g} \mathrm{~kg}^{-1}$ de areia grossa, $370 \mathrm{~g} \mathrm{~kg}^{-1}$ de areia fina, $210 \mathrm{~g} \mathrm{~kg}^{-1}$ de silte e $300 \mathrm{~g} \mathrm{~kg}^{-1}$ de argila.

$\mathrm{O}$ experimento foi implantado durante o período de inverno do ano de 2013, com plantio no mês 
de agosto, num delineamento experimental de blocos casualizados (DBC), com quatro repetições. As ocorrências meteorológicas verificadas durante o período de condução dos experimentos, nos anos de 2013 e 2014, estão apresentadas nas Figuras 1 e 2, respectivamente. Os tratamentos consistiram de seis valores de tensão matricial da água do solo $(20 \mathrm{kPa}, 40 \mathrm{kPa}$, $60 \mathrm{kPa}, 80 \mathrm{kPa}, 100 \mathrm{kPa}$ e $120 \mathrm{kPa}$ ), testadas em uma cultivar de milho.

Foi utilizado o híbrido duplo AG 1051 que possui ciclo semi-precoce, em torno de 115 dias, de grão amarelo e dentado, alta resistência ao acamamento, desenvolvido para produção de grãos, silagem e milho verde (Castro, 2010).

Utilizou-se o método convencional de preparo do solo, com uma aração e uma gradagem leve em pré-plantio. Em seguida, a área foi sulcada e adubada, utilizando-se um espaçamento de $0,7 \mathrm{~m}$ entre linhas. A adubação foi constituída de $300 \mathrm{~kg} \mathrm{ha}^{-1} \mathrm{da}$ fórmula 8-28-16 aplicado no sulco de plantio. As unidades experimentais consistiram de três linhas de $5 \mathrm{~m}$ de comprimento, sendo considerada como área útil a linha central. O plantio foi realizado manualmente e foi feito desbaste quando as plantas estavam com três a quatro folhas totalmente expandidas, ajustando a densidade populacional para 67.000 plantas por hectare,

Todas as medidas nutricionais e fitossanitárias foram tomadas de acordo com as necessidades da cultura. O controle de plantas daninhas foi realizado por método químico, com aplicação dos herbicidas recomendados.

Após o plantio, todas as parcelas tiveram a umidade do solo elevada à capacidade de campo, quando então foram aplicados os tratamentos. O experimento contou com irrigação feita por meio de um sistema de gotejamento, com vazão de $2,5 \mathrm{~L} \mathrm{~h}^{-1}$.
Durante o período de aplicação dos tratamentos, sempre que a tensão de água no solo atingiu o limite de tensão estabelecido, o sistema de irrigação do tratamento foi acionado para atender às tensões testadas. As irrigações foram realizadas para elevar a tensão da água do solo a $10 \mathrm{kPa}$, sendo realizadas leituras diárias de tensão com auxílio do sensor de resistência elétrica de matriz granular da marca Watermark ${ }^{\circledR}$.

A tensão da água no solo foi medida por meio de blocos de resistência elétrica, instalados ao lado das linhas centrais das parcelas, na profundidade de $0,20 \mathrm{~m}$. A quantidade de água reposta em cada irrigação foi obtida com o auxílio da curva de retenção de água do solo da área experimental.

Foram avaliadas as variáveis produtividade de espigas sem palha (PESP), número total de espigas na parcela (NET), número de espigas comerciais (NEC), comprimento de espigas com palha (CEP) e sem palha (CE) e diâmetro de espigas comerciais (DE).

Para a avaliação do peso de espigas sem palha (PESP) foram colhidas espigas da parcela útil, sendo estas identificadas e pesadas sem palha, com auxílio de uma balança analítica, e o resultado foi expresso em toneladas por hectare.

O número total de espigas na parcela (NET) foi determinado no momento da colheita, contabilizando-se o número total de espigas na parcela útil de cada tratamento, sendo o resultado transformado para hectare.

Para determinar o número de espigas comerciais (NEC) foram consideradas espigas comercializáveis aquelas que apresentaram diâmetro igual ou maior que 3,0 cm e comprimento igual ou maior que $15,0 \mathrm{~cm}$, eliminando-se as pequenas, mal granadas ou danificadas. Segundo Paiva Júnior et al. (2001), se enquadram no padrão comercial espigas sem palha, 


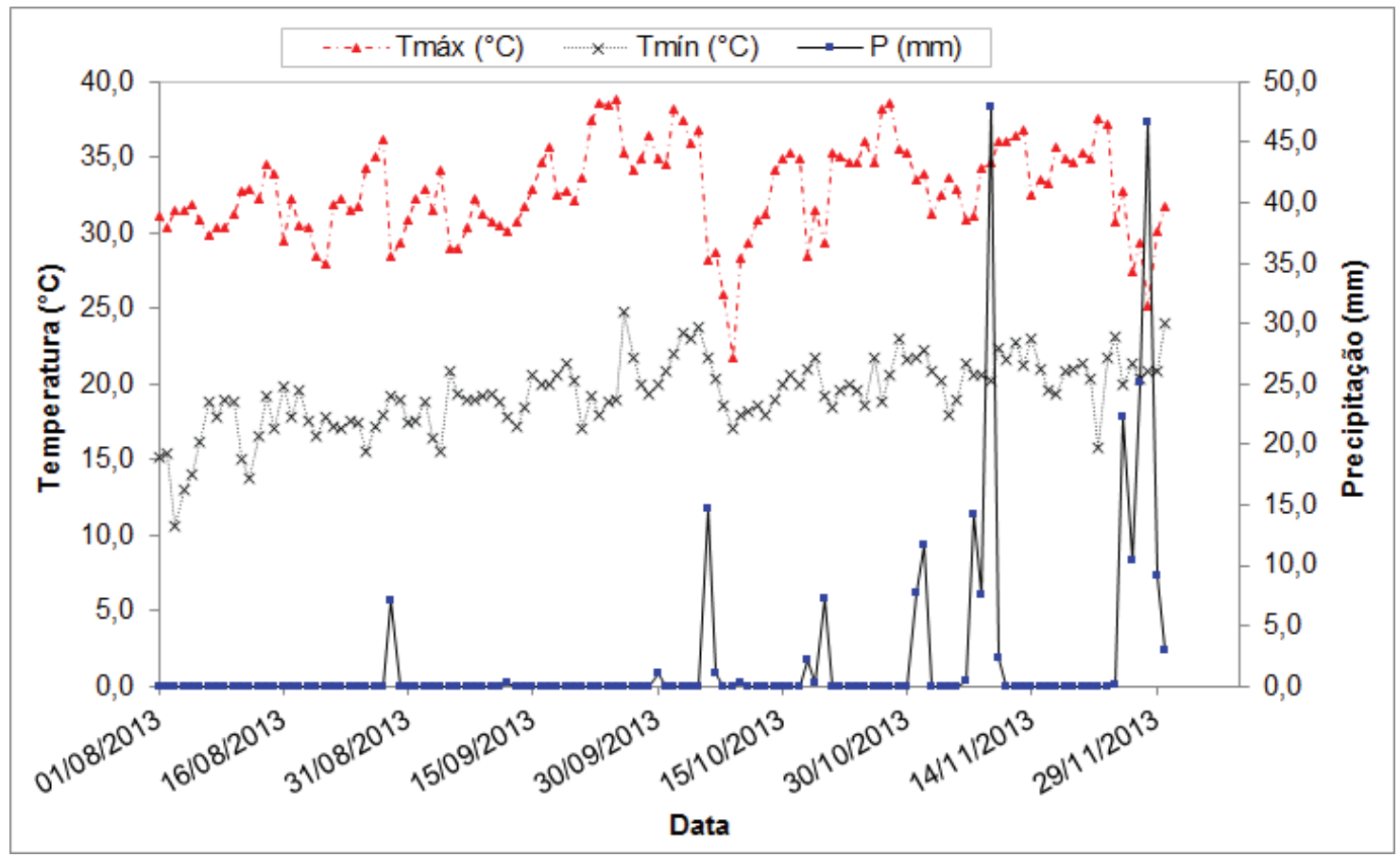

Figura 1. Dados de temperatura e precipitação no período de condução do experimento em Nova Porteirinha MG, fornecidos pelo INMET - Instituto Nacional de Meteorologia, no ano de 2013.

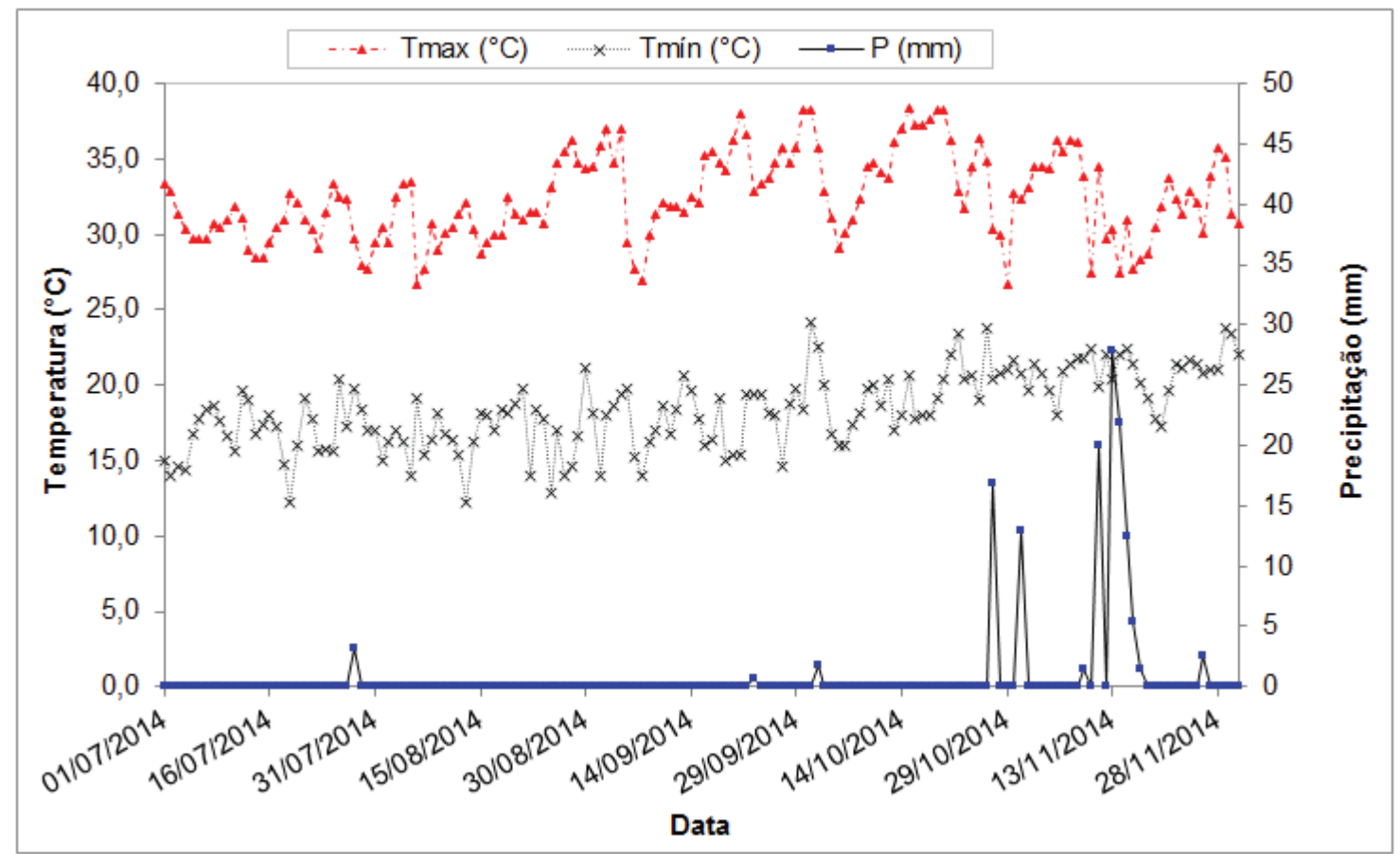

Figura 2. Dados de temperatura e precipitação no período de condução do experimento em Nova Porteirinha MG, fornecidos pelo INMET - Instituto Nacional de Meteorologia, no ano de 2014. 
com diâmetro e comprimento superior a 3,0 e $15 \mathrm{~cm}$, respectivamente.

O comprimento de espigas com palha (CEP) e sem palha (CE) foi determinado com auxílio de régua graduada, sendo o resultado expresso em $\mathrm{cm}$.

O diâmetro de espigas comerciais (DE) foi determinado na parte central de cada espiga comercial com auxílio de um paquímetro e o resultado expresso em $\mathrm{cm}$.

Os dados obtidos foram submetidos à análise de variância por meio do programa Sisvar (Ferreira, 2011). Em caso de significância das fontes de variação, as diferenças observadas foram estudadas por meio de análise de regressão, escolhendo-se os modelos em função do comportamento da variável avaliada e da significância dos coeficientes da equação e do valor do $\mathrm{R}^{2}$.

\section{Resultados e Discussão}

Foi verificada relação quadrática entre os valores de produtividade de espigas despalhadas e as ten- sões de água no solo (Figura 3). Observou-se acréscimo no peso de espigas despalhadas com o uso de baixas tensões de água no solo, a partir da tensão de $20 \mathrm{kPa}$, até a tensão de $53,4 \mathrm{kPa}$, cuja produtividade máxima foi igual a $4,59 \mathrm{t} \mathrm{ha}^{-1}$.

Quando se trata de produção de milho verde, o peso de espigas sem palha é uma das variáveis mais importantes na determinação da quantidade de água adequada fornecida à cultura.

Também houve relação quadrática significativa entre os valores do número total de espigas e as diferentes tensões matriciais (Figura 4), sendo observados acréscimos no número total de espigas por hectare com o uso da tensão de 42,4, que apresentou produção total de 35.600 espigas ha ${ }^{-1}$. Nascimento (2012), trabalhando com características agronômicas do milho verde sob diferentes regimes hídricos em Teresina/PI, obteve valores para número de espigas por hectare de 37.292 e 29.749 , com aplicação das maiores lâminas de água de $125 \%$ da ETo e $100 \%$ ETo, respectivamente, valores bem próximos aos observados nesse estudo.

Tabela 1. Resumo da análise de variância para os resultados das características produtividade de espigas sem palha (PESP), número total de espigas na parcela (NET), número de espigas comerciais (NEC), comprimento de espigas com palha (CEP) e sem palha (CE) e diâmetro de espigas comerciais (DE). Considerando os seis valores testados de tensão matricial da água do solo (20 kPa, $40 \mathrm{kPa}, 60 \mathrm{kPa}, 80 \mathrm{kPa}, 100 \mathrm{kPa}$ e $120 \mathrm{kPa})$. Nova Porteirinha - MG, 2014.

\begin{tabular}{|c|c|c|c|c|c|c|c|}
\hline \multicolumn{8}{|c|}{$\mathrm{QM}$} \\
\hline $\mathrm{FV}$ & GL & $\begin{array}{c}\text { PESP } \\
\text { (ton } \mathrm{ha}^{-1} \text { ) }\end{array}$ & 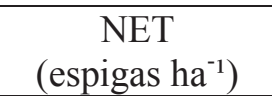 & 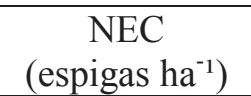 & $\begin{array}{l}\text { CEP } \\
(\mathrm{cm})\end{array}$ & $\begin{array}{l}\mathrm{CE} \\
(\mathrm{cm})\end{array}$ & $\begin{array}{l}\mathrm{DE} \\
(\mathrm{cm})\end{array}$ \\
\hline Trat. & 5 & $2.283 * *$ & $73756363.975 * *$ & 18502789.166* & $12.580 * *$ & $2.854 *$ & $0.106^{* *}$ \\
\hline Bloco & 3 & $0.253^{\mathrm{ns}}$ & $2169089.375^{\mathrm{ns}}$ & $8162766.5^{\mathrm{ns}}$ & $0.744^{\mathrm{ns}}$ & $0.281^{\mathrm{ns}}$ & $0.007^{\mathrm{ns}}$ \\
\hline Erro & 15 & 0.162 & 6514967.308 & 4898263.1 & 1.218 & 0.879 & 0.018 \\
\hline Total & 23 & & & & & & \\
\hline Média & & 3.998 & 32736.375 & 21904.583 & 26.434 & 17.768 & 4.304 \\
\hline $\mathrm{CV}(\%)$ & & 10.08 & 7.8 & 10.10 & 4.18 & 5.28 & 3.15 \\
\hline
\end{tabular}

** $(\mathrm{P} \leq 0,01) ; *(\mathrm{P} \leq 0,05) ;{ }^{\text {ns }}$ não significativo. 


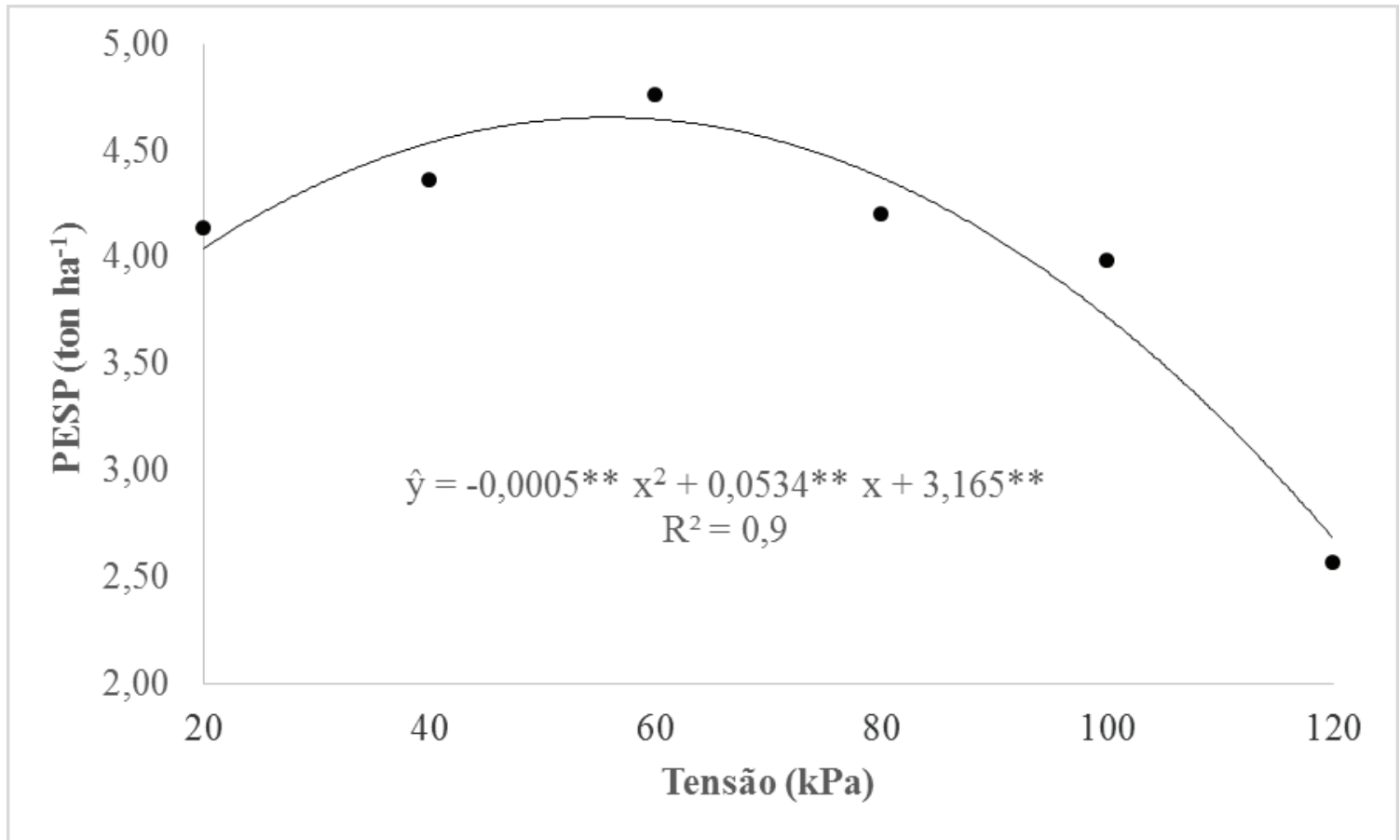

Figura 3. Produtividade de espigas sem palha (PESP) de milho verde em função de diferentes tensões de água do solo. Nova Porteirinha - MG, 2014.

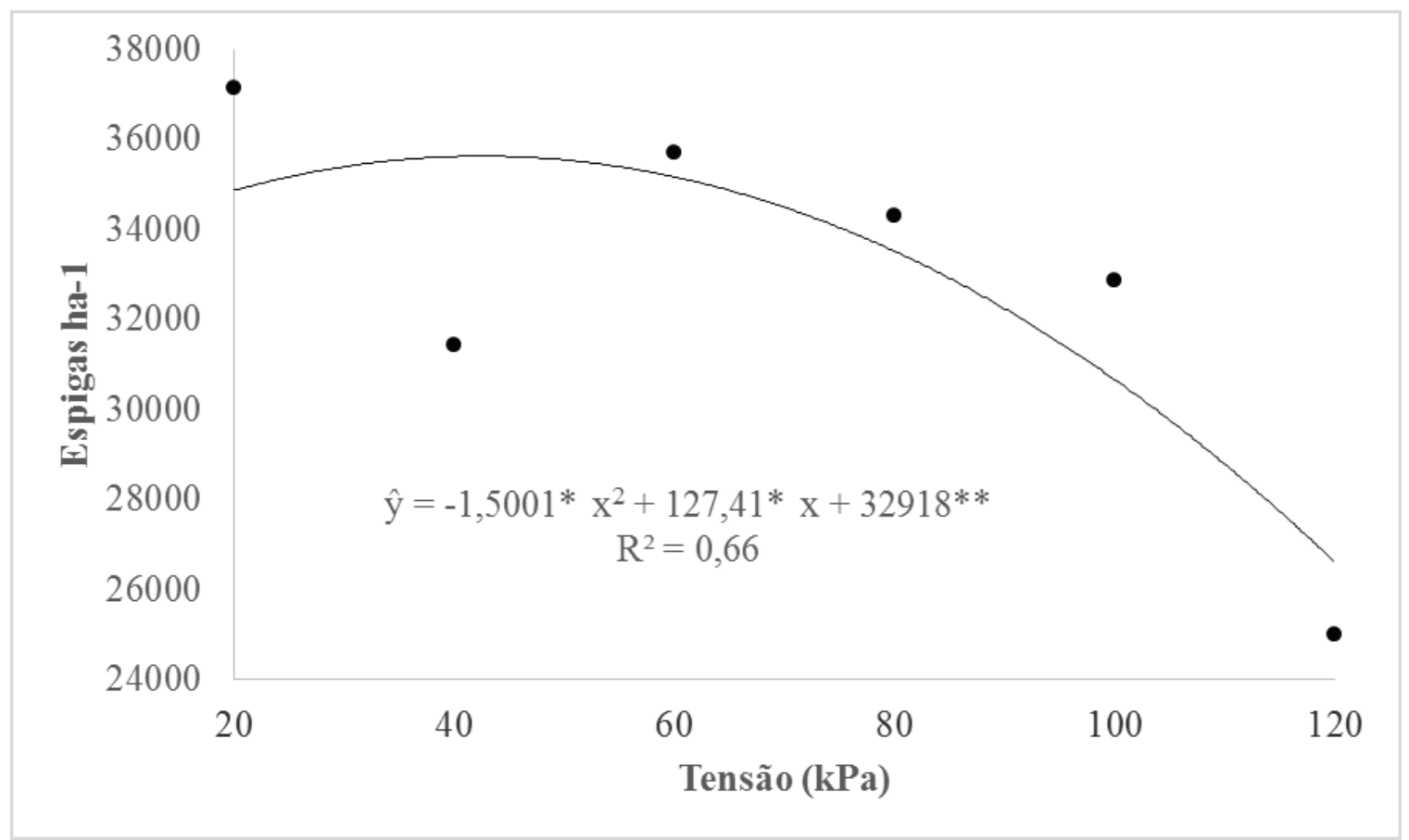

Figura 4. Número de espigas totais (NET) de milho verde em função de diferentes tensões de água do solo. Nova Porteirinha - MG, 2014. 
Biscaro et al. (2008), estudando a influência da aplicação de água no milho verde irrigado na região do Cerrado Sul-Mato-Grossense, concluíram que a quantidade de água aplicada não proporcionou alterações significativas no número de espigas produzidas por hectare.

Comrelaçãoaonúmero de espigasverdes comerciais por hectare, foram observados acréscimos com o uso da tensão de $64,4 \mathrm{kPa}$, que apresentou produção máxima de 23.660 espigas comerciais ha-1 (Figura 5).

Meneghetti et al. (2008), ao avaliar a aplicação de lâminas de irrigação em cultivo de minimilho em São Miguel do Iguaçu/PR, determinadas pela evapotranspiração da cultura, não verificou diferença significativa entre os manejos de água utilizados para a característica número de espiguetas aceitáveis comercialmente.

Quando comparado o rendimento de número de espigas comerciais ao número total de espigas, foi verificada baixa produção de espigas comerciais quando mantidas tensões de água no solo próximas à tensão de $20 \mathrm{kPa}$ e $120 \mathrm{kPa}$. Esses resultados evidenciam que solos próximos da capacidade de campo $(20 \mathrm{kPa})$ e muito secos (100 e $120 \mathrm{kPa})$ afetam diretamente o desenvolvimento das espigas (Figuras 4 e 5).

O comprimento de espigas empalhadas sofreu acréscimos com o uso de baixas até relativamente altas tensões de água no solo; a partir da tensão de 20 $\mathrm{kPa}$ observou-se comprimento médio de $27,15 \mathrm{~cm}$ e à tensão de $100 \mathrm{kPa}$ comprimento de 26,00 cm (Figura 6). O máximo comprimento de espigas com palha $(27,7 \mathrm{~cm})$ foi observado na tensão de $38,9 \mathrm{kPa}$.

O conhecimento do comprimento da espiga empalhada e sem palha do milho verde é um item importante na escolha da cultivar, além de ser uma característica indicativa de qualidade na comercialização (Vieira et al., 2010).
Os valores de comprimento encontrados para as espigas verdes apresentam-se dentro dos padrões para serem enquadradas como comerciais, conforme relato de Cardoso et al. (2011), que classificaram espigas verdes empalhadas do híbrido duplo comercial AG 1051 com comprimentos de 26,4 cm como adequadas para comercialização in natura no município de Teresina-PI.

Resultados encontrados por Von Pinho et al. (2008) no município de Sete Lagoas, para comprimento de espiga com palha, sem a imposição de déficit hídrico, apresentaram média superior a $31 \mathrm{~cm}$, valor superior aos encontrados neste trabalho, mesmo em baixas tensões de água no solo.

Os valores de comprimento de espigas sem palha $(\mathrm{cm})$ não variaram muito em função das diferentes tensões de água impostas (Figura 7). Foi observado máximo comprimento de espigas sem palha $(18,32$ $\mathrm{cm})$ quando mantida tensão de $73 \mathrm{kPa}$.

Paiva Júnior et al. (2001) e Santos et al. (2005) sugerem que ao serem despalhadas as espigas comerciais apresentam comprimento maior que $15 \mathrm{~cm}$. Seguindo este critério, o comprimento de espigas sem palha mostrou-se dentro dos padrões exigidos para comercialização, em todos os tratamentos.

Rivera-Hernández et al. (2010), afirmam que decréscimos no comprimento da espiga como consequência de deficiência hídrica podem estar relacionados à diminuição da fotossíntese.

Analisando os resultados obtidos para os valores de diâmetro de espigas comerciais (Figura 8), observa-se uma resposta linear para o diâmetro em função dos tratamentos adotados, sendo os melhores resultados obtidos quando mantidas baixas tensões de água do solo, com valores médios de diâmetro de 4,45 a $4,05 \mathrm{~cm}$, respectivamente, para as tensões de 20 e $120 \mathrm{kPa}$. 


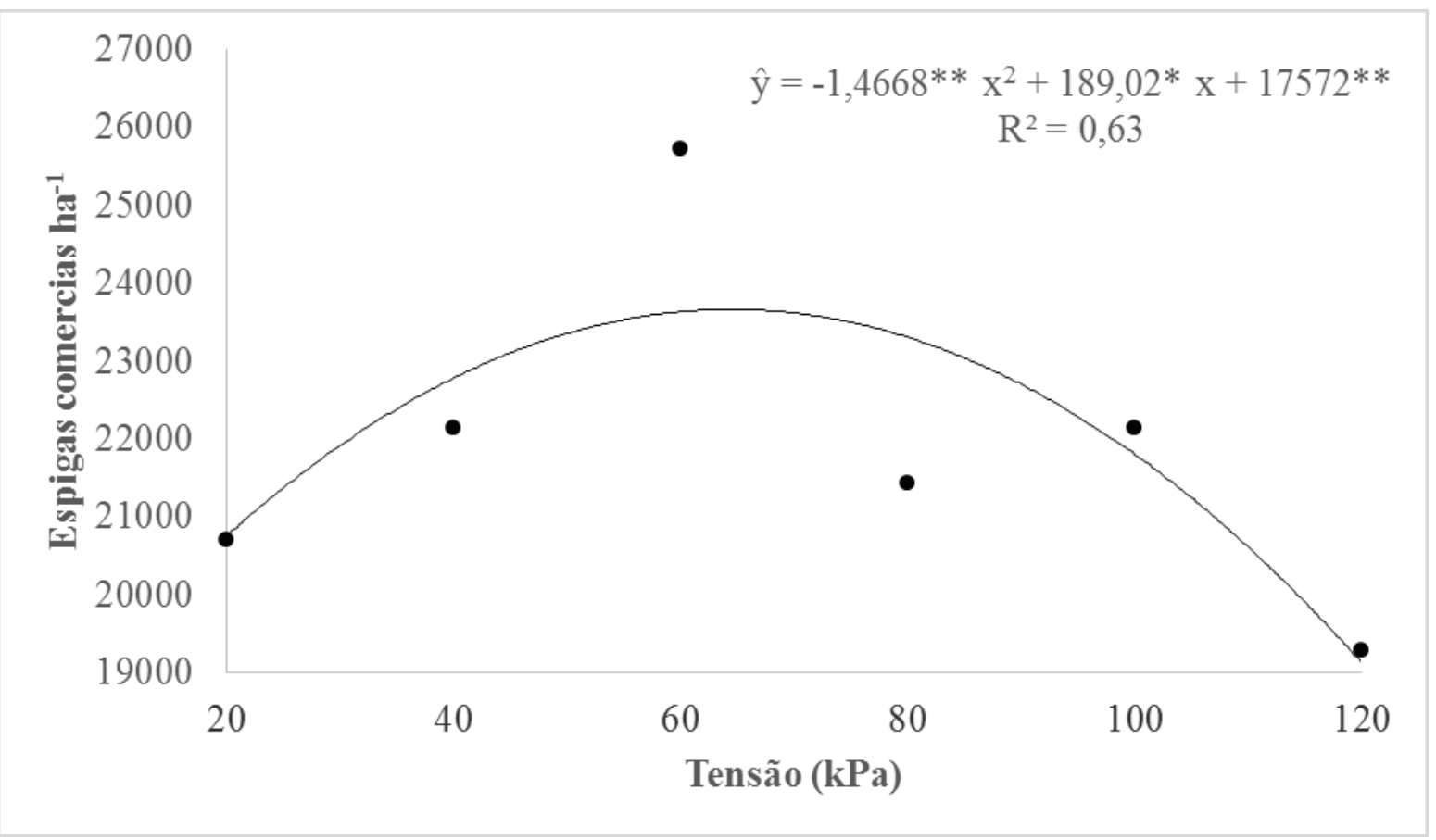

Figura 5. Número de espigas comerciais (NEC) de milho verde em função de diferentes tensões de água do solo. Nova Porteirinha - MG, 2014.

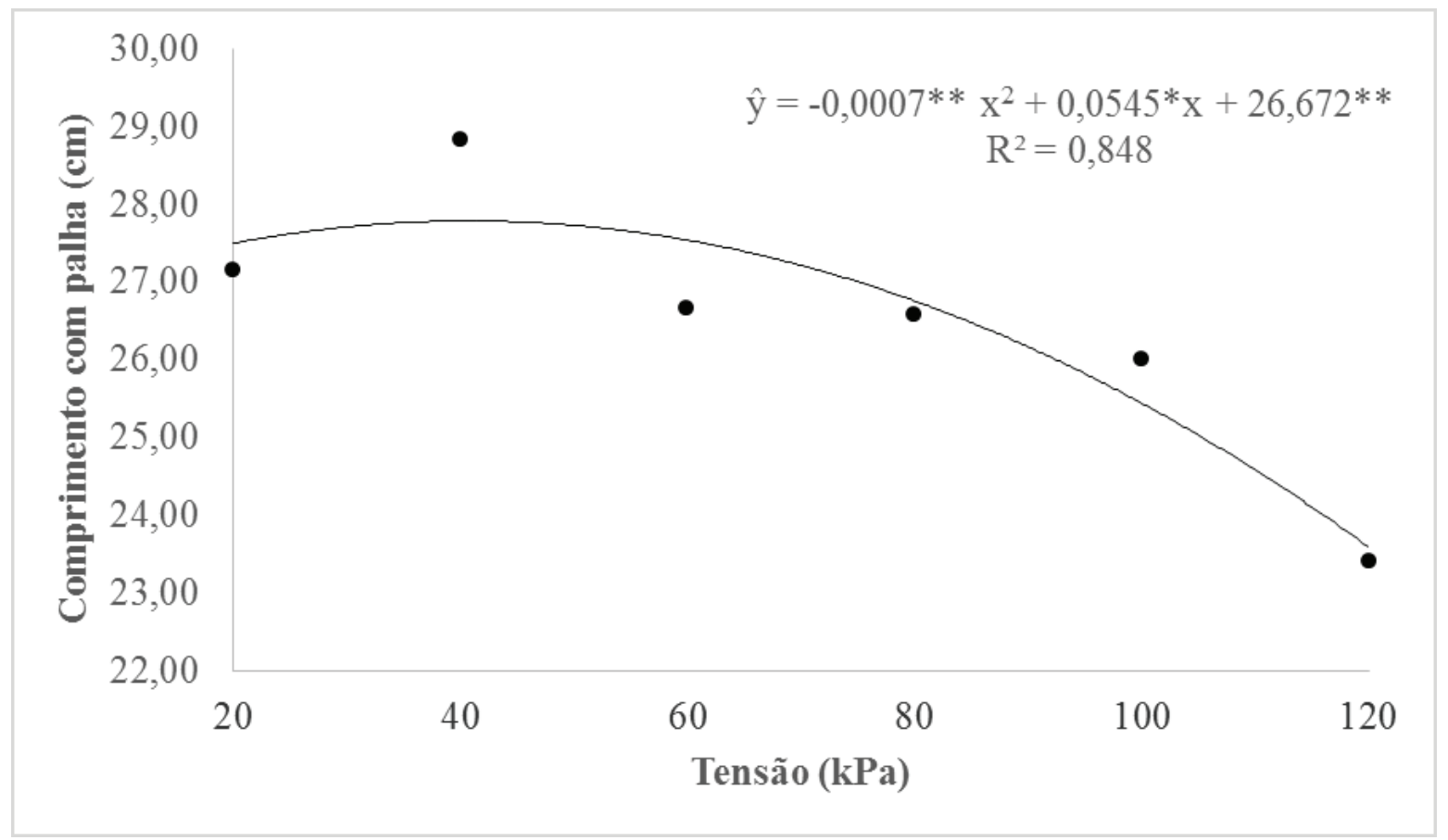

Figura 6. Comprimento de espigas de milho verde com palha (CEP) em função de diferentes tensões de água do solo. Nova Porteirinha - MG, 2014. 


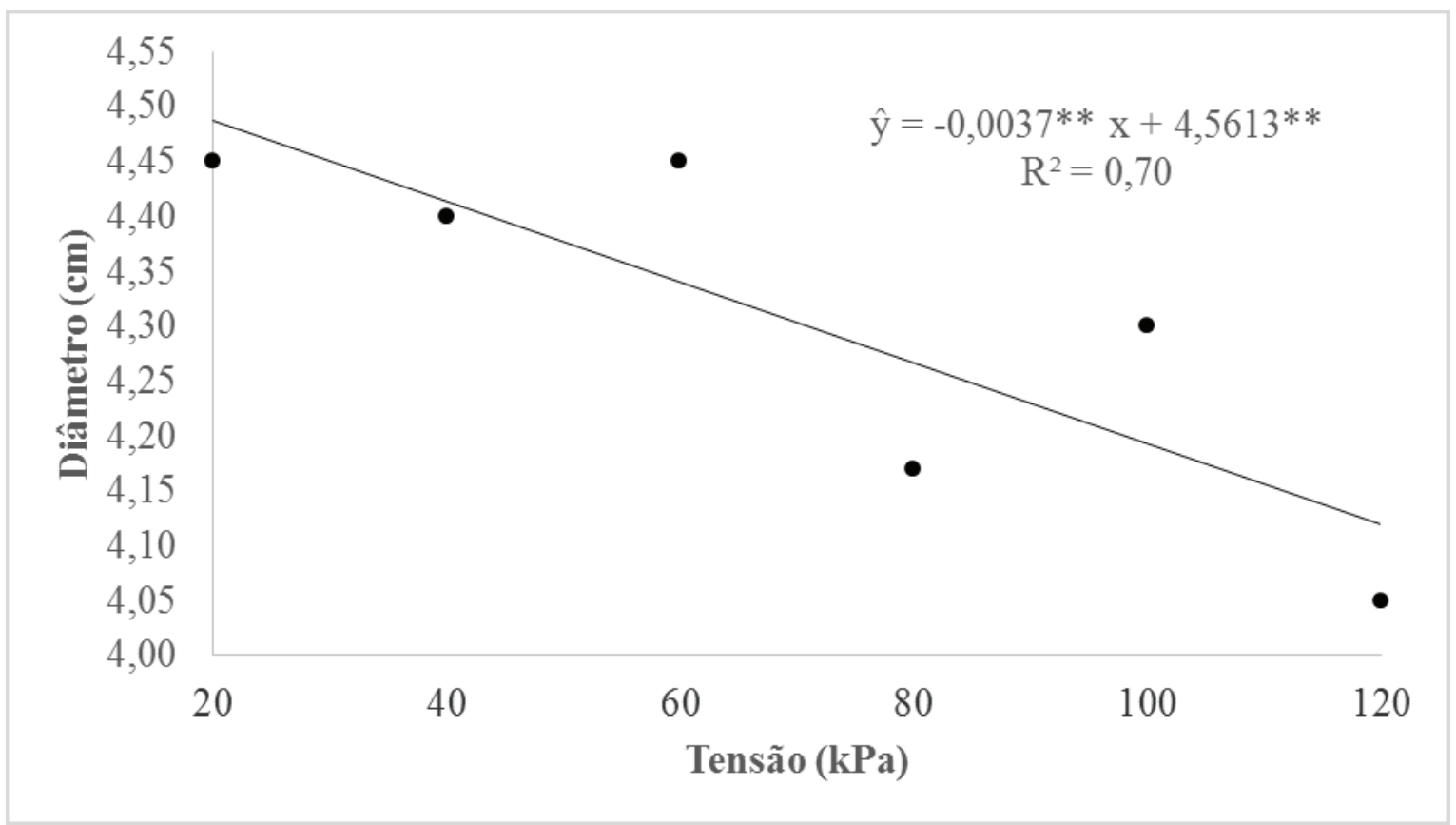

Figura 7. Comprimento de espigas de milho verde sem palha (CE) em função de diferentes tensões de água do solo. Nova Porteirinha - MG, 2014.

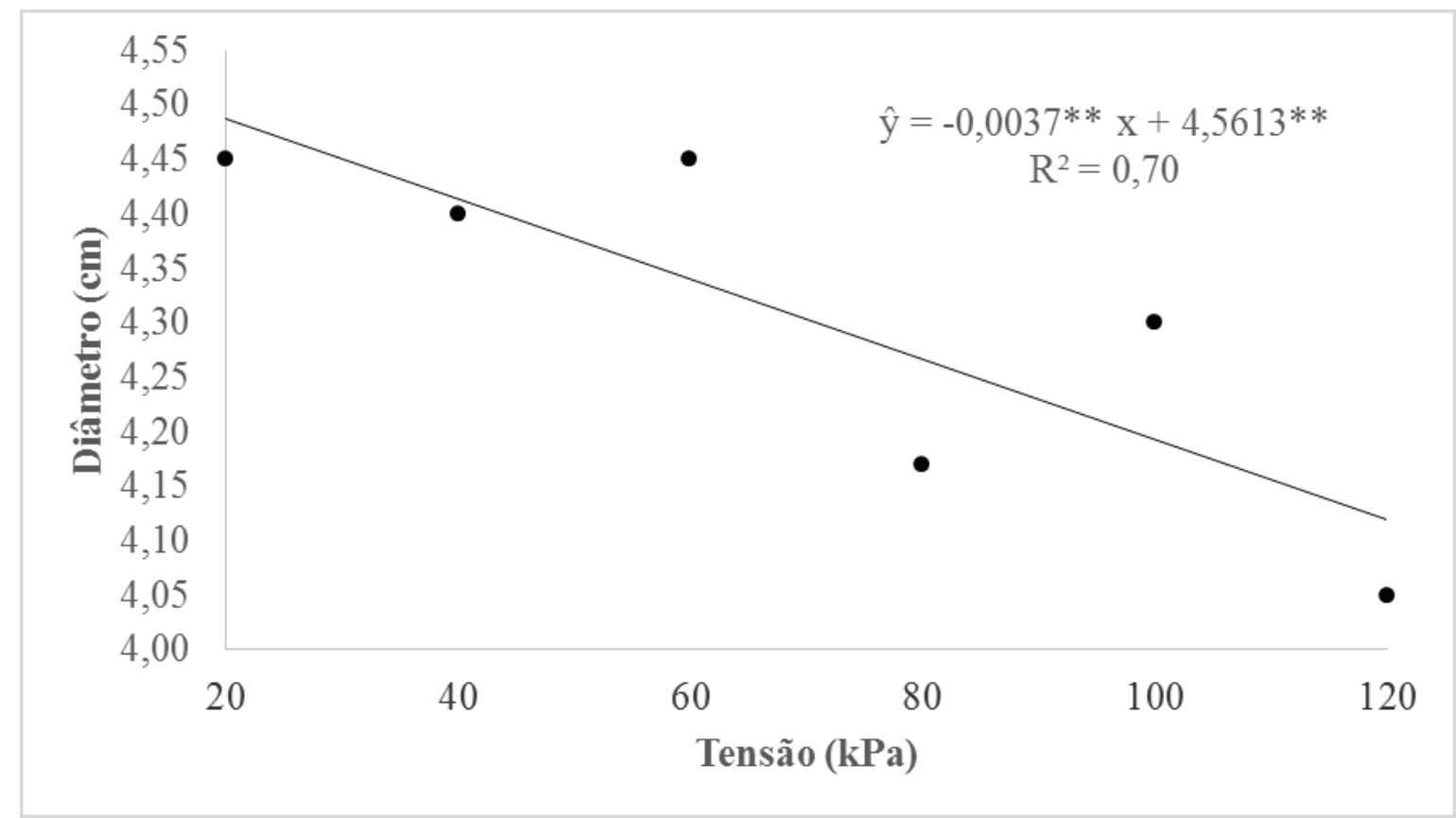

Figura 8. Diâmetro de espigas comerciais (DE) de milho verde em função de diferentes tensões de água do solo. Nova Porteirinha - MG, 2014. 
O diâmetro médio das espigas é uma das características importantes para o comércio do milho verde (Paiva Júnior et al., 2001). Também segundo estes autores, as espigas são caracterizadas como comerciais quando o diâmetro for superior a 3,0 cm e estiverem isentas de pragas e doenças. Santos et al. (2005) consideraram que apenas espigas de milho verde com diâmetro mínimo de $3 \mathrm{~cm}$, são consideradas comercializáveis.

Os melhores valores de diâmetro obtidos quando submetidos a tensões de 20, 40 e $60 \mathrm{kPa}$, foram $4,45 \mathrm{~cm}, 4,40 \mathrm{~cm}$ e 4,45 cm, respectivamente, apesar de não terem diferirdo muito dos demais tratamentos.

Efeito linear da lâmina de irrigação sobre esta variável também foi observado por Biscaro et al. (2008), que obtiveram $3,7 \mathrm{~cm}, 3,7 \mathrm{~cm}, 3,5 \mathrm{~cm}$ e $3,4 \mathrm{~cm}$ para $200 \%, 100 \%, 50 \%$ e $25 \%$ do tempo de irrigação, respectivamente.

Valores superiores aos encontrados no presente trabalho foram observados por Freire et al. (2010) em Prudente de Morais, MG, para diâmetro médio de espiga sem palha entre 4,65 cm e 4,95 cm em resposta a doses de nitrogênio, e por Sousa et al. (2015) em Teresina, PI, que obtiveram valores médios de $4,81 \mathrm{~cm}$ e 4,75 cm para diâmetro de espiga de milho sem palha com ciclo de 70 dias. Esses valores são referentes aos espaçamentos de $0,6 \mathrm{~m}$ e $0,8 \mathrm{~m}$, densidades de 5,50 e 6,25 plantas $\mathrm{m}^{-2}$ e uma lâmina de irrigação de $433 \mathrm{~mm}$.

Os resultados deste trabalho apresentam subsídios para o manejo ideal da irrigação na condução da cultura do milho verde nas condições climáticas do semiárido, podendo contribuir para o aumento da produtividade e para a otimização desta atividade na região, além de reduzir o consumo de água utilizado.

$\mathrm{O}$ entendimento de como as plantas respondem a episódios de seca e de rega e dos mecanismos envolvidos é notavelmente útil na implantação de prá- ticas de manejo de irrigação em tempos de mudanças climáticas (Xu et al., 2010).

\section{Conclusão}

A tensão de água no solo, para reinício da irrigação, que propicia os maiores incrementos das variáveis é de $50 \mathrm{kPa}$, sendo a tensão mais adequada para o uso racional da água no manejo da irrigação do milho verde.

\section{Agradecimentos}

À FAPEMIG, CAPES e CNPq pelas bolsas concedidas e apoio financeiro.

\section{Referências}

BISCARO, G. A.; MAIA, S. C. M.; SILVA, T. R. B. da. Influência da aplicação de água no milho verde irrigado na região do cerrado Sul-Mato-Grossense. Revista Agrarian, Dourados, MS, v. 1, n. 1, p. 67-77, jul./set. 2008.

CASTRO, R. S. de. Rendimento de espigas verdes e de grãos de cultivares de milho após a colheita da primeira espiga como minimilho. 2009. 90 f. Tese (Doutorado em Fitotecnia) - Universidade Federal Rural do Semi-Árido, Mossoró-RN, 2010.

CARDOSO, M. J.; RIBEIRO, V. Q.; MELO, F. B. Performance de cultivares de milho-verde no município de Teresina, Piaú. Embrapa Meio-Norte, 2011. 4 p. (Embrapa Meio-Norte. Comunicado Técnico, 227).

FERREIRA, D. F. Sisvar: a computer statistical analysis system. Ciência e Agrotecnologia, Lavras, v. 35, n. 6, p. 1039-1042, 2011.

DOI: $10.1590 /$ S1413-70542011000600001.

FREIRE, F. M.; VIANA, M. C. M.; MASCARENHAS, M. H. T.; PEDROSA, M. W.; COELHO, A. M.; ANDRADE, 
C. de L. T. de. Produtividade econômica e componentes da produção de espigas verdes de milho em função da adubação nitrogenada. Revista Brasileira de Milho e Sorgo, Sete Lagoas, v. 9, n. 3, p. 213-222, 2010. DOI: 10.18512/1980-6477/rbms.v9n3p213-222.

MENEGHETTI, A. M.; SANTOS, R. F.; NÓBREGA, L. H. P.; MARTINS, G. L. Análise de crescimento de minimilho submetido a lâminas de irrigação. Acta Scientiarum Agronomy, Maringá, v. 30, n. 2, p. 211-216, 2008. DOI: 10.4025 /actasciagron.v30i2.1730.

NASCIMENTO, F. N. do. Características agronômicas do milho verde sob diferentes regimes hídricos. 2012. 82 f. Dissertação (Mestrado em Agronomia) - Universidade Federal do Piauí, Teresina, 2012.

OMETTO, J. C. Bioclimatologia vegetal. São Paulo: Agronômica Ceres, 1981. 440 p.

PAIVA JÚNIOR, M. C. de; VON PINHO, R. G.; VON PINHO, E. V. de R.; RESENDE, S. G. de. Desempenho de cultivares para a produção de milho verde em diferentes épocas e densidades de semeadura em Lavras, MG. Ciência e Agrotecnologia, Lavras, v. 25, n. 5, p. 1235-1247, 2001.

RIVERA-HERNÁNDEZ, B.; CARRILLO-AVILA, E.; OBRADOR-OLAN, J. J.; JUAREZ-LOPEZ, J. F.; ACEVES-NAVARRO, L. A. Morphological quality of sweet corn (Zea mays L.) ears as response to soil moisture tension and phosphate fertilization in Campeche, Mexico. Agricultural Water Management, Amsterdam, v. 97, n. 9, p. 1365-1374, 2010. DOI: 10.1016/j.agwat.2010.04.001.
SANTOS, I. C.; MIRANDA, G. V.; MELO, A. V.; MATTOS, R. N.; OLIVEIRA, L. R.; LIMA, J. da S.; GALVÃO, J. C. C. Comportamento de cultivares de milho produzido organicamente e correlações entre características das espigas colhidas no estádio verde. Revista Brasileira de Milho e Sorgo, Sete Lagoas, v. 4, n. 1, p. 45-53, 2005.

DOI: 10.18512/1980-6477/rbms.v4n1p45-53.

SOUSA, R. S.; BASTOS, E. A.; CARDOSO, M. J.; RIBEIRO, V. Q.; BRITO, R. R. Desempenho produtivo de genótipos de milho sob déficit hídrico. Revista Brasileira de Milho e Sorgo, Sete Lagoas, v. 14, n. 1, p. 49-60, 2015. DOI: 10.18512/1980-6477/rbms.v14n1p49-60.

VIEIRA, M. de A.; CAMARGO, M. K.; DAROS, E.; ZAGONEL, J.; KOEHLER, H. S. Cultivares de milho e população de plantas que afetam a produtividade de espigas verdes. Acta Scientiarum. Agronomy, Maringá, v. 32, n. 1, p. 81-86, 2010.

DOI: $10.4025 /$ actasciagron.v32i1.987.

VON PINHO, L. de; PAES, M. C. D.; ALMEIDA, A. C de; COSTA, C. A da. Qualidade de milho verde cultivado em sistemas de produção orgânico e convencional. Revista Brasileira de Milho e Sorgo, Sete Lagoas, v. 7, n. 3, p. 279-290, 2008.

DOI: 10.18512/1980-6477/rbms.v7n3p279-290.

XU, Z.; ZHOU, G.; SHIMIZU, H. Plant responses to drought and rewatering. Plant Signaling \& Behaviour, v. 5, n. 6, p. 649-654, 2010.

DOI: $10.4161 / \mathrm{psb} \cdot 5 \cdot 6.11398$. 